\title{
10-(pyren-1-yl)-10h-phenothiazine and pyrene as organic catalysts for photoinitiated ATRP of 4-vinylpyridine
}

\author{
Loc Tan Nguyen', Hung Quang Pham¹, Duc Anh Song Nguyen', Luan Thanh Nguyen¹, Ky Phuong Ha Huynh², \\ Hai Le Tran², Phong Thanh Mai ${ }^{2}$, Ha Tran Nguyen ${ }^{1,3^{*}}$ (D), Le-Thu Thi Nguyen ${ }^{1,3}$, Thuy Thu Truong ${ }^{1,3^{* *}}$ \\ 'National Key Laboratory of Polymer and Composite Materials, Ho Chi Minh City University of Technology
- HCMUT, Vietnam National University-Ho Chi Minh City - VNU-HCM, Ho Chi Minh City, Vietnam \\ ${ }^{2}$ Faculty of Chemical Engineering, Ho Chi Minh City University of Technology - HCMUT, Vietnam National \\ University - Ho Chi Minh City - VNU-HCM, 268 Ly Thuong Kiet, District 10, Ho Chi Minh City, Vietnam \\ ${ }^{3}$ Faculty of Materials Technology, Ho Chi Minh City University of Technology - HCMUT, Vietnam National \\ University - Ho Chi Minh City - VNU-HCM, Ho Chi Minh City, Vietnam \\ *nguyentranha@hcmut.edu.vn; **trtthuy@hcmut.edu.vn
}

\begin{abstract}
The UV light-mediated metal-free polymerizations of 4-vinylpyridine (4VP) have been successfully performed by using 10-(pyren-1-yl)-10H-phenothiazine (PPTh) and pyrene as photocatalysts. The preparation of narrow polydispersity poly (4-vinyl pyridine) (P4VP) with high conversions was enabled in both protic as well as unprotic reaction media at ambient temperature. Additionally, copolymerizations of 4VP with acrylate and methacrylate monomers were also demonstrated, affording metal-free copolymer products.
\end{abstract}

Keywords: organic photocatalyst, metal-free atom transfer radical polymerization, 4-vinylpyridine, pyrene.

How to cite: Nguyen, L. T., Pham, H. Q., Nguyen, D. A. S., Nguyen, L. T., Huynh, K. P. H., Tran, H. L., Mai, P. T., Nguyen, H. T., Nguyen, L. T., \& Truong, T. T. (2021). 10-(pyren-1-yl)-10h-phenothiazine and pyrene as organic catalysts for photoinitiated ATRP of 4-vinylpyridine. Polímeros: Ciência e Tecnologia, 31(1), e2021001. https://doi. org/10.1590/0104-1428.08120

\section{Graphical Abstract}

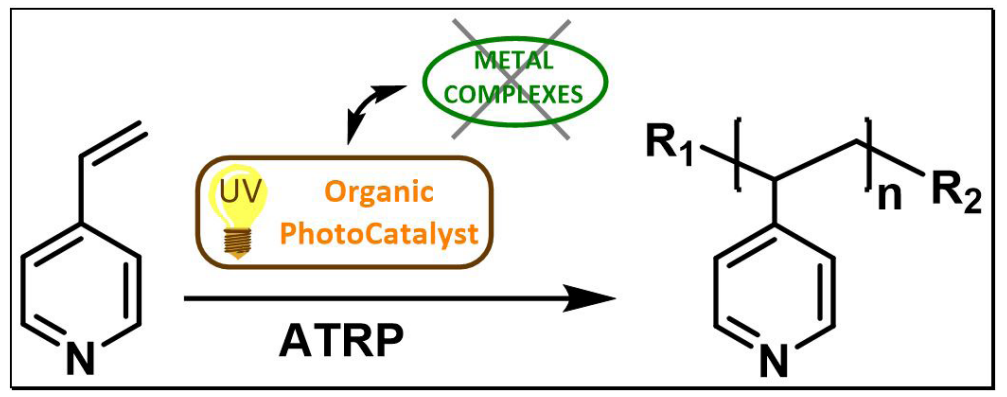

\section{Introduction}

Pyridine-ring is an attractive chemical structure which possesses not only an annular enclosed conjugated system but also one $\mathrm{sp}^{2}$ hybrid orbital on the nitrogen atom, occupied by one lone pair of electron. Because this pair of electrons is excluded from the aromaticity, it can bind with the protons; therefore, pyridine is alkaline and could also coordinate with transition metal ions to form complexes ${ }^{[1,2]}$. With these special properties above, pyridine contained polymers have caught much attention of scientists for various applications, for example dye sensitized solar cell ${ }^{[3]}$, $\mathrm{pH}$-responsive materials ${ }^{[4]}$, block copolymer micelles used in drug delivery ${ }^{[5]}$, moreover, they are capable of forming self-assembly supramolecular structures via nitrogen atoms on the pyridine ring ${ }^{[1]}$. Materials use for applications above are typically based on poly (4-vinylpyridine) (P4VP) or copolymers of 4-vinylpyridine (4VP) and other monomers depending on specific purposes.

Typical methodologies to synthesize polymers from $4 \mathrm{VP}$ are free radical polymerization ${ }^{[6,7]}$, living anionic polymerization $^{[8]}$, and controlled radical polymerizations (CRPs) including nitroxide-mediated polymerization $(\mathrm{NMP})^{[9]}$, reversible addition fragmentation chain transfer polymerization $(\mathrm{RAFT})^{[10,11]}$ and atom transfer radical 
polymerization $(\mathrm{ATRP})^{[2,3,12]}$. Nowadays, polymer chemistry has been significantly developing and the polymerization methods are required to produce polymers with high quality such as narrow polydispersity index (PDI) as well as control molecular weight. Therefore, CRPs have recently become the most common routes to gain polymers with mentioned criteria though there are some difficulties which scientists have to deal with ${ }^{[13]}$, such as the high-temperature requirement of $\mathrm{NMP}^{[14]}$ or unavoidable radical termination events of RAFT ${ }^{[15]}$. Regarding ATRP, although it has been successfully employed for the synthesis of various polymers with well-defined structure ${ }^{[16]}$. Polymerization of polar monomers, especially of 4VP, via traditional ATRP method is challenging due to the strong coordination between pyridine rings and ligands that can compete with the binding of the metal catalysts in these systems ${ }^{[2]}$. Thus the selection of solvents as well as catalyst complexes is very tricky. Additionally, ATRP has the drawback of metal contamination in products ${ }^{[17]}$ leading to the limitation in electronic and biomedical applications.

In recent years, the development of organic photo-catalysts (o-PC) has emerged as a powerful tool to solve the issue of residual metal in the products ${ }^{[18,19]}$. In 2014, Hawker et al. first presented a metal-free ATRP of methyl methacrylate using 10-phenylphenothiazine as an o-PC ${ }^{[20]}$. After that, $\mathrm{K}$. Matyjaszewski's group reported three phenothiazine derivatives as catalysts used for photo-induced polymerization of acrylonitrile in $2015^{[21]}$. Very recently, in April 2018, our group developed (10-(pyren-1-yl)-10H-phenothiazine (PPTh) as the effective o-PC for the metal-free ATRP of several monomers including methyl methacrylate, N,N-dimethylamino2-ethyl methacrylate, 2-([4,6- dichlorotriazin-2-yl] oxy) ethyl methacrylate as well as a copolymerization of methyl methacrylate and 1-pyrenemethyl methacrylate ${ }^{[18]}$. In 2018, Miyake's research group reported the novel photocatalyst of $N, N$-diaryl dihydrophenazines can be applied for both metal-free ATRP and PET-RAFT polymerization to obtain the diblock copolymers of PMA- $b$-PMMA via both PET-RAFT and metal free-ATRP in sequence ${ }^{[22,23]}$. Especially, o-PC is expected to be used for the synthesis of pyridine polymers, because of the absence of metal complex catalyst system. ATRP using o-PC does not require the use of ligand so that choice of solvent is much more facile. To our knowledge, despite the potential of o-PC, this method has not been applied to the preparation of pyridine polymers yet.

Thus, in this work, we demonstrate the novel metal-free photo-induced polymerization as the facile methodology for polymer preparations from $4 \mathrm{VP}$, which could solve the issue of residual metal in the product of previous ATRP systems. In particular, phenothiazine derivative (10-(pyren1-yl)-10H-phenothiazine (PPTh)) and pyrene were used as $\mathrm{o}-\mathrm{PCs}$ for the polymerizations of $4 \mathrm{VP}$.

We also employed these o-PC to synthesis copolymers of 4VP with stearyl methacrylate and stearyl acrylate as the models of acrylate and methacrylate monomers. We chose these two monomer because of the challenging polymerization as well as interesting applications based on their self-assembly ability. We believe this study will remove the difficulties of traditional ATRP and contribute the new facile methodology for polymer preparation from $4 \mathrm{VP}$.

\section{Materials and Methods}

\subsection{Materials}

4-vinylpyridine (4VP, 95\%), stearyl acrylate (SA, 97\%), stearyl methacrylate (SMA, 97\%) were purchased from Sigma Aldrich and passed through an alumina column to remove inhibitor; pyrene (Sigma Aldrich, 98\%), ethyl 2-bromo-2-methylpropionate (Initiator) (Sigma Aldrich, 98\%); tetrahydrofuran (THF, 99.8\%, no stabilizer) was purchased from Acros Organics, methanol (99.9\%), ethanol (99.5\%), diethyl ether (99\%) were purchased from Fisher and used as received; 10-(pyren-1-yl)-10H-phenothiazine (PPTh) was prepared via the route provided by Nguyen et al. ${ }^{[18]}$.

\subsection{Polymer Preparation}

Polymerization reactions were carried out in UV box at room temperature (RT) in two-neck flasks, they were flamed three times and filled with $\mathrm{N}_{2}$ before chemicals were added into. Monomer(s), solvent(s), catalyst and initiator were respectively added into the flask under nitrogen. The mixture was stirred at RT for 15 minutes and degassed with three freeze-pump-thaw cycles. The reaction system was flushed with nitrogen then the polymerization was carried out in UV box (a $365 \mathrm{~nm}$ UV light, $12 \times 9$ watt bulbs, intensity of $2.2 \mathrm{~mW} \mathrm{~cm}{ }^{-2}$ determined by a VLX365 radiometer) while the mixture was kept continuously stirred. After the time indicated, UV light was turned off and the mixture was stirred in the dark for 30 minutes for stabilization. Then, the polymer was precipitated twice in cold diethyl ether and dried under vacuum until remain weight. After being dried under vacuum, the yellowish powder was received as the final product of the synthesis of P4VP.

\subsection{Characterizations}

${ }^{1} \mathrm{H}$ NMR spectra were recorded in deuterated chloroform $\left(\mathrm{CDCl}_{3}\right)$ with TMS as an internal reference, on a Bruker Avance $500 \mathrm{MHz}$ spectrometer. Gel permeation chromatography (GPC) measurements were performed on a Polymer PL-GPC 50 gel permeation chromatograph system equipped with an RI detector; DMF containing $0.1 \mathrm{~mol} / \mathrm{L}$ of lithium bromide as the eluent at a flow rate of $1.0 \mathrm{~mL} / \mathrm{min}$, molecular weights and molecular weight distributions were calculated with reference to polystyrene standards. FT-IR spectra, collected as the average of 64 scans with a resolution of $4 \mathrm{~cm}-1$, were recorded from $\mathrm{KBr}$ disk on a FT-IR Bruker Tensor 27. Differential scanning calorimetry (DSC) measurements were carried out with a DSC Q20 V24.4 Build 116 calorimeter under nitrogen flow, at a heating rate of $10^{\circ} \mathrm{C} / \mathrm{min}$.

\section{Results and Discussions}

The photoinitiated ATRP has been performed under nitrogen environment under UV irradiation system at $365 \mathrm{~nm}$ using suppercure 352S, SAN-EI ELECTRIC CO., Osaka, Japan.

Figure 1 presents a proposed general photoinitiated ATRP mechanism ${ }^{[13,19,20,22]}$ : under UV light irradiation, o-PC is activated to excited state (o-PC*) which is able reduce the alkyl bromide initiator or subsequent polymer chain ends. This process is capable to form o- $\mathrm{PC}+/ \mathrm{Br}$ - complex 
as well as a carbon centered propagating radical species allowing polymerization in the presence of monomers. The deactivation of $\mathrm{o}-\mathrm{PC}^{+} / \mathrm{Br}^{-}$complex could oxidize the propagating radical to regenerate the alkyl bromide and the original state of o-PC which temporarily ends a propagation cycle. Subsequently, the photoexcitation of the o-PC to $\mathrm{o}-\mathrm{PC}^{*}$ reinitiates the new propagation cycles contributing to the formation of long-chain and well-defined polymers.

The synthetic routes of polymers in this study were summarizes as Scheme 1.

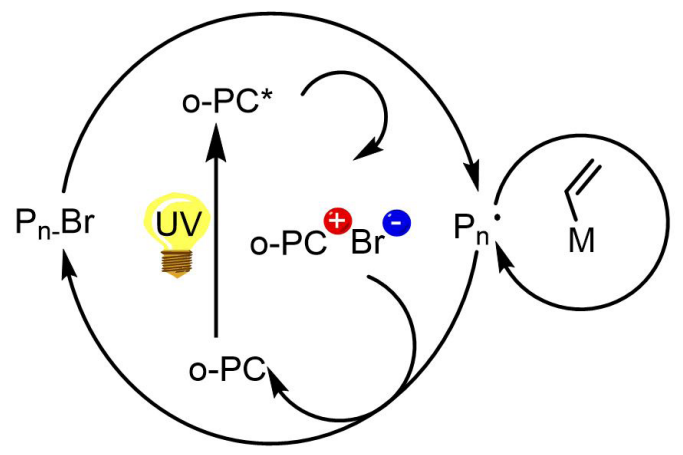

Figure 1 A proposed general photoinitiated ATRP mechanism $\left(\mathrm{P}_{\mathrm{n}}=\right.$ polymer chain)

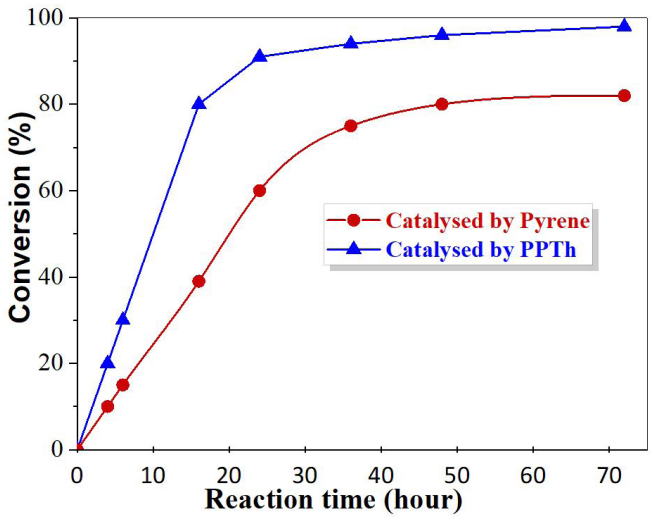

* Polymerizations was carried out under a $365 \mathrm{~nm}$ UV irradiation

Figure 2. Conversion of polymerizations of 4VP during time catalyzed by Pyrene and PPTh

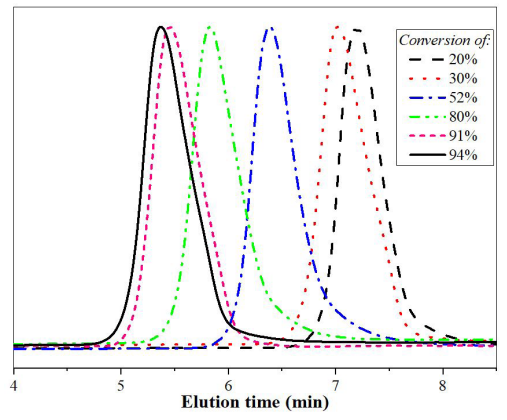

* Polymerizations was carried out under a $365 \mathrm{~nm}$ UV irradiation

\subsection{Preparation of P4VP}

\subsubsection{Effect of solvents}

Table 1 (entry 1-7) summarizes the results of the polymerization of $4 \mathrm{VP}$ in different reaction media.

Three solvents, with a dielectric constants are nearly the same, including ethanol, methanol, THF are used as the sample of protic and aprotic polar reaction media. After 24-hour reaction, PPTh showed the high catalyst efficiency in ethanol and methanol, which results in high monomer conversions (Table 1, entry $1-2$ ) compared to traditional ATRP ${ }^{[2]}$. These results could be explained by the good solubility of both 4VP and P4VP in alcohol solvents. Additionally, polymer products gave PDI below 1.2 which indicated good controllable polymerizations.

Furthermore, to examine whether the polymerization using o-PC could improve the strict solvent selection or not, the mixed solvent of THF (as the unprotic solvent) and ethanol with different fractions was used (Table 1, entry 3-5). The conversion almost remained constant with the ratio of THF and ethanol was 1:1 (v/v) but it began decreasing when we used more THF in the mixture and this value was just $65 \%$ when absolute THF was used. However, conversions could reach $92 \%$ after polymerizing in THF for $48 \mathrm{~h}$ (Table 1, entry 6). So that it could be concluded that the unprotic solvent were possibly used as the reaction media although the reaction rate might fall. The same effect was received in pyrene catalyst systems though the conversions were lower in the same reaction time (Table 1, entry 7-9).

\subsubsection{Effect of photo-catalyst}

The reactions using PPTh or pyrene were conducted in ethanol to compare the effect of catalysts on the polymerization and the results are illustrated in Figure 2. The new phenothiazine derivative - PPTh showed better catalyst efficiency. The monomer conversion of reaction using PPTh gradually increased to $91 \%$ after $24 \mathrm{~h}$ compare to $60 \%$ of the one catalyzing by commercial catalyst pyrene. When expanding the reaction time, because of the increase of reaction mixture viscosity, conversions slowly grew to $94 \%$ and $80 \%$ for PPTh and pyrene system respectively then level off. GPC traces of P4VP synthesized using PPTh as photocatalyst (Figure 3a) showed the shift in elution time vs monomer conversion indicating the

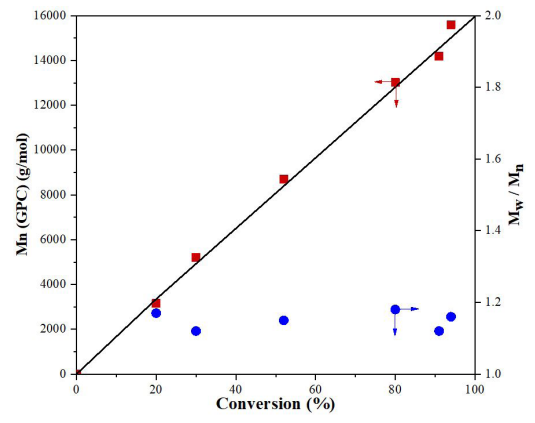

(b)

Figure 3. (a)) GPC traces vs conversions of P4VP synthesized using PPTh as photocatalyst in ethanol (b) Dependence of molecular weight $\left(M_{n}, G P C\right)$ and polydispersity $\left(M_{w} / M_{n}\right)$ on monomer conversion. 


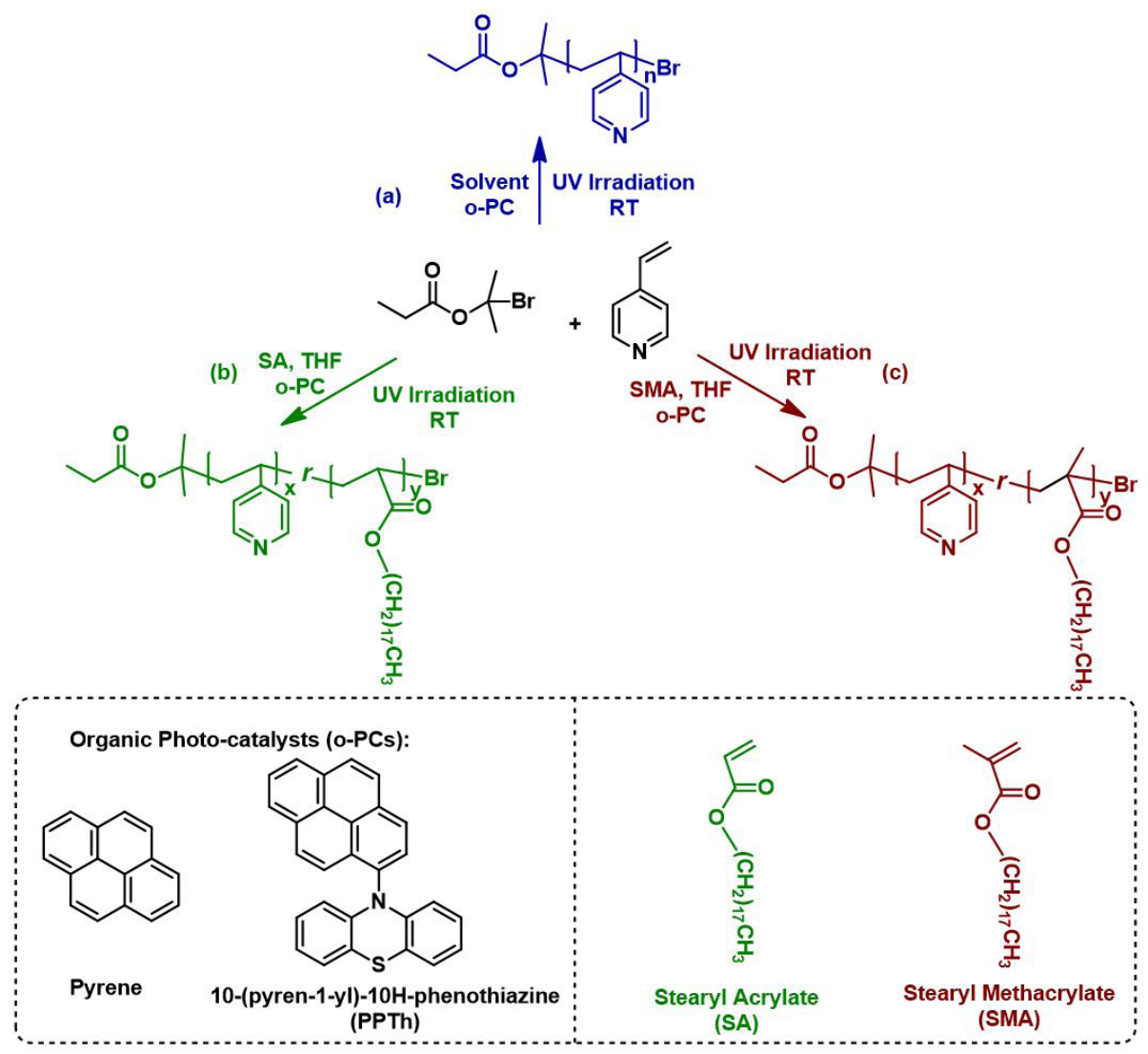

Scheme 1. Synthetic pathways of P4VP (a), P(4VP-r-SA) (b), P(4VP-r-SMA) using o-PCs.

Table 1. Results of photo-induced metal-free ATRP of 4VP*.

\begin{tabular}{|c|c|c|c|c|c|c|c|c|}
\hline Entry & Monomer & {$[4 \mathrm{VP}]_{0}:[\mathrm{I}]_{0}:[\mathrm{C}]_{0}$} & Solvent & Catalyst & Time (h) & $M_{n}{ }^{b}(g / m o l)$ & PDI $^{\mathbf{b}}$ & Conv $^{\mathrm{a}}(\%)$ \\
\hline 1 & $4 \mathrm{VP}$ & 150:1:0.1 & Ethanol & PPTh & 24 & 14,186 & 1.12 & 91 \\
\hline 2 & $4 \mathrm{VP}$ & $150: 1: 0.1$ & Methanol & PPTh & 24 & 14,260 & 1.09 & 90 \\
\hline 3 & $4 \mathrm{VP}$ & $150: 1: 0.1$ & THF: Ethanol $(1 / 1 \mathrm{v} / \mathrm{v})$ & PPTh & 24 & 14,450 & 1.12 & 90 \\
\hline 4 & $4 \mathrm{VP}$ & $150: 1: 0.1$ & THF: Ethanol $(7 / 2 \mathrm{v} / \mathrm{v})$ & PPTh & 24 & 12,323 & 1.19 & 75 \\
\hline 5 & $4 \mathrm{VP}$ & $150: 1: 0.1$ & THF & PPTh & 24 & 10,750 & 1.18 & 65 \\
\hline 6 & $4 \mathrm{VP}$ & $150: 1: 0.1$ & THF & PPTh & 48 & 14,225 & 1.11 & 92 \\
\hline 7 & $4 \mathrm{VP}$ & $150: 1: 1$ & Ethanol & Pyrene & 24 & 9,257 & 1.15 & 60 \\
\hline 8 & $4 \mathrm{VP}$ & $150: 1: 0.1$ & Methanol & Pyrene & 24 & 9,442 & 1.16 & 58 \\
\hline 9 & $4 \mathrm{VP}$ & $150: 1: 0.1$ & THF & Pyrene & 24 & 7,201 & 1.12 & 45 \\
\hline 10 & 4VP, SA (2:1) & $100: 1: 0.1$ & THF & PPTh & 48 & 6,804 & 1.77 & 71 \\
\hline 11 & 4VP, SMA (2:1) & 100:1:0.1 & THF & PPTh & 48 & 11,670 & 1.59 & 78 \\
\hline
\end{tabular}

*Polymerizations was carried out under a $365 \mathrm{~nm} \mathrm{UV}$ irradiation; ${ }^{a}$ Conversion was determined gravimetrically: conversion $=\left(\mathrm{m}^{\left.-\mathrm{m}_{\mathrm{1}}-\mathrm{m}_{\mathrm{PC}}\right) /}\right.$ $\mathrm{m}_{\mathrm{M}}$ where $\mathrm{m}$ denotes the weight of product, and $\mathrm{m}_{\mathrm{l}}, \mathrm{m}_{\mathrm{PC}}, \mathrm{m}_{\mathrm{M}}$ are the weights of the initiator, photocatalyst and monomers, respectively. ${ }^{\mathrm{b}} \mathrm{PDI}$, $M_{n}$ were determined by GPC.

increase in polymer molecular weight. Kinetic plot for the PPTh-catalyzed polymerization (Figure $3 b$ ) showed linear increase in molecular weight with conversion indicating the "living" nature of the chain growth process. In addition, the polydispersity of the obtained polymers maintained a low level at around 1.2 which is the important factor of CRPs.

\subsubsection{Photo-controllable polymerization}

To illustrate the temporal control of polymerization by UV light, the ON/OFF experiment was carried out (Figure 4). The model polymerization experiments using a ratio of [4VP]/
$[\mathrm{I}] /[\mathrm{PPTh}]$ or $[4 \mathrm{VP}] /[\mathrm{I}] /[$ Pyrene $]=150 / 1 / 0.1$ were conducted in ethanol. After the reaction mixtures was repaired in a flasks (2.2), they were taken into the UV box then UV light system was operated to repeated circles of 3-hour UV-ON and 1-hour UV-OFF. At each interval, equivalent volumes of samples were syringed out from the polymerization system and precipitated into excess cold diethyl ether to gravimetrically determine the conversions. Results indicated the polymerizations were ultimately irradiation dependent and there was almost no monomer consumption occurred in UV-OFF periods either PPTh or pyrene was used as o-PC. 
3.2 Preparation of random copolymers $P(4 V P-r-S A)$ and $P(4 V P-r-S M A)$

As can be seen from the Table 1 (entry 10,11), polymerizations occurred with the yields of $71 \%$ for $\mathrm{P}(4 \mathrm{VP}-\mathrm{r}-$ SA) and $78 \%$ for P(4VP-r-SMA) after $48 \mathrm{~h}$.

As the result of GPC (Table 1, entry 10-11), P(4VP-r$\mathrm{SA})$ and $\mathrm{P}(4 \mathrm{VP}-\mathrm{r}-\mathrm{SMA})$ were afforded with $\mathrm{M}_{\mathrm{w}}$ values of 12,032 as 18,556 as well as PDI of 1.77 and 1.59 respectively. The polydispersity was much higher than the one of P4VP homopolymer. The use of two monomers in the systems

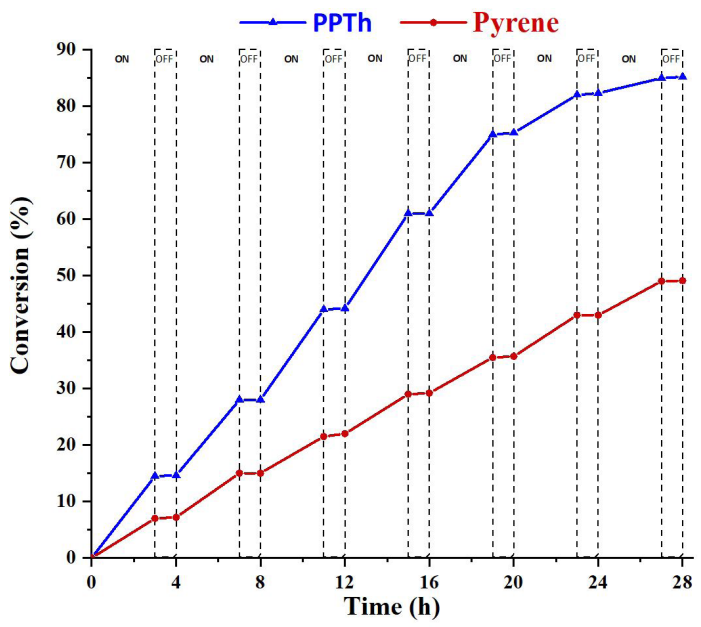

* Polymerizations was carried out under a $365 \mathrm{~nm}$ UV irradiation

Figure 4. Monomer conversion vs. time in ON-OFF experiments demonstrating photo-controlled polymerization propagation using PPTh (blue triangle line) and pyrene (red dot line) might lead to an unstable propagation and that could be the cause of this inconvenience.

The chemical structure of these copolymers were characterized by ${ }^{1} \mathrm{H}-\mathrm{NMR}$ measurement (Figure 5 ). In both ${ }^{1} \mathrm{H}-\mathrm{NMR}$ spectra, two broad proton signals at $\delta 8.15-8.6$ and $\delta 6.27-7.07 \mathrm{ppm}$ which contributed to the meta- and orthoprotons of pyridine rings, respectively. In addition, signals in the range of $\delta 2.87-4.08 \mathrm{ppm}$ that assigned to methylene protons $\left(-\mathrm{O}-\mathrm{CH}_{2}-\right)$ from stearyl groups. The resonance signals observed in the regions between $1.00-2.61 \mathrm{ppm}$ indicated the protons in copolymer backbones and $-\mathrm{CH}_{2}-[\mathrm{CH} 2]_{15}$ - in stearyl groups. Methyl protons $\left(\mathrm{CH}_{3}\right)$ of stearyl groups in P(4VP-r-SA) or of stearyl and methacrylate groups in $\mathrm{P}(4 \mathrm{VP}-r$-SMA) contributed to the peaks below $1.00 \mathrm{ppm}$ in the spectra. Moreover, by measuring the relative intensities of meta-protons from pyridine ring $(\mathrm{d}, 2 \mathrm{H})$ and of methylene protons $(\mathrm{e}, 2 \mathrm{H})$ from stearyl group, molar ratio of two units in copolymers could be calculated, particularly, the fraction of $4 \mathrm{VP} / \mathrm{SA}$ in $\mathrm{P}(4 \mathrm{VP}-r$-SA) was 1.12 and the value of $4 \mathrm{VP} /$ SMA in $\mathrm{P}(4 \mathrm{VP}-r$-SMA) was 1.37 , whereas the feeding ratio of $4 \mathrm{VP}$ over SA (or SMA) was $2 / 1$.

P4VP received was analyzed by FTIR (Figure 6) illustrating the characteristic vibration of pyridine ring which evidenced by the absorption bands at $1596.99 \mathrm{~cm}^{-1}$. Moreover, the absorption bands at 1068.52 and $993.30 \mathrm{~cm}^{-1}$ were observed to confirm the in-plane and out-of-plane rings $\mathrm{C}-\mathrm{H}$ bending, respectively ${ }^{[24]}$. Absorption band of $\mathrm{C}=\mathrm{O}$ at $1730 \mathrm{~cm}^{-1}$ in of poly (stearyl acrylate) and poly (stearyl methacrylate) were slightly broadened to the lower wavenumber might cause of the hydrogen bonding of $\mathrm{C}=\mathrm{O}$ and pyridine in the copolymer. Moreover, the formation of hydrogen bonding

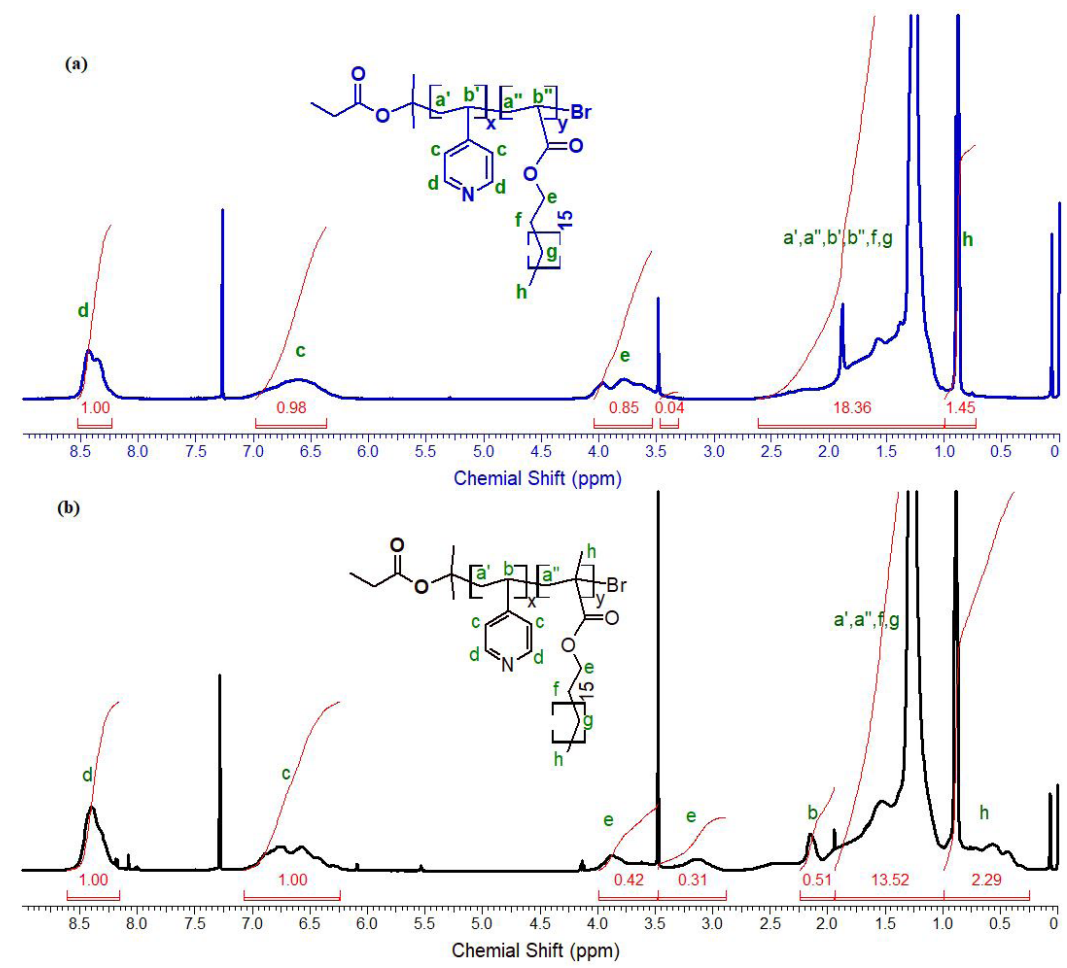

Figure 5. ${ }^{1} \mathrm{H}-\mathrm{NMR}$ spectra of (a) $\mathrm{P}(4 \mathrm{VP}-\mathrm{r}-\mathrm{SA})$ and (b) P(4VP-r-SMA). 


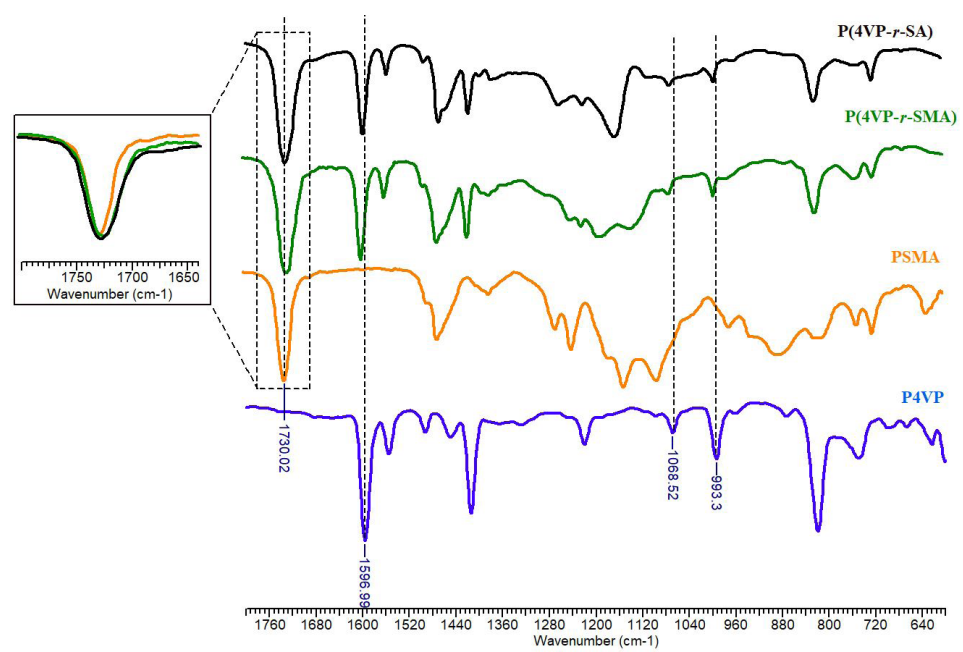

Figure 6. FTIR spectrum of P(4-vinylpyridine) (blue line), Poly (stearyl methacrylate) (orange line), Poly (4-Vinylpyridine-r-Steary acrylate) (black line) and Poly (4-Vinylpyridine-r-Stearylmethacrylate) (green line).
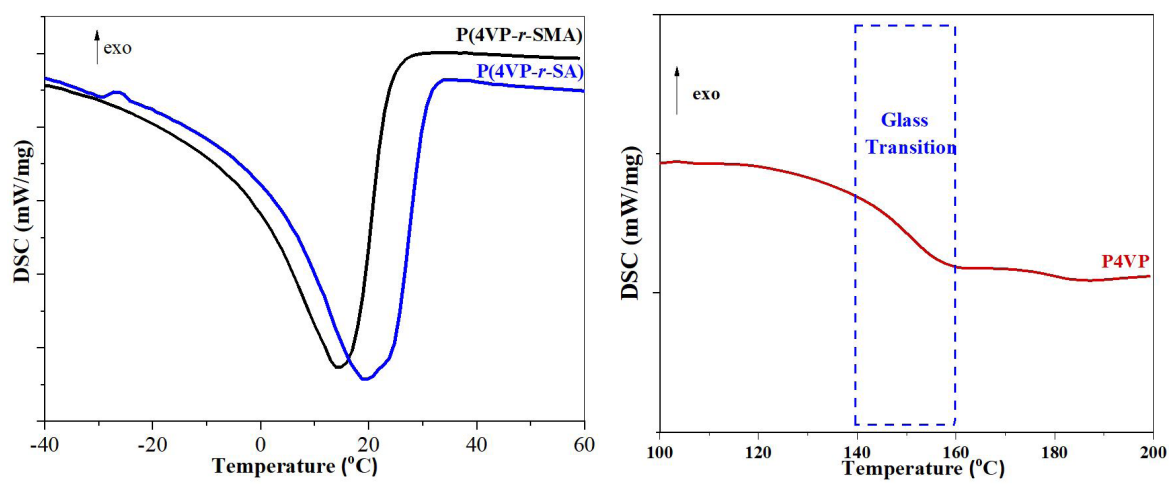

Figure 7. Differential scanning calorimetry (DSC) curve of P4VP product.

also slightly shifted the deformation band of pyridine at $1068.52 \mathrm{~cm}^{-1}$ to $1070.45 \mathrm{~cm}^{-1}$.

Thermal properties was also testified by DSC (Figure 7) demonstrating the melting point of stearyl groups at $15{ }^{\circ} \mathrm{C}$ and $20^{\circ} \mathrm{C}$ of $\mathrm{P}(4 \mathrm{VP}-r$-SMA $)$ and $\mathrm{P}(4 \mathrm{VP}-r$-SA $)$, respectively. In addition, DSC curve also showed the glass transition of P4VP at a temperature between 140 and $160^{\circ} \mathrm{C}^{[25]}$.

\section{Conclusions}

Metal-free polymerization of $4 \mathrm{VP}$ as well as copolymerization with acrylate and methacrylate monomers have been successfully constructed by using PPTh and pyrene as organic photocatalysts. The preparations of P4VP could be controlled under irradiation which produce products with high conversion and very narrow PDI $(<1.2)$ with no metal contamination. In addition, the reactions were not only possibly carried out in protic media but also unprotic solvent like THF, which is the limitation of traditional ATRP.

\section{Acknowledgement}

This research is funded by Vietnam National University Hochiminh City (VNU-HCM) under grant number C201920-19.

\section{References}

1. Chen, Y., Zhao, W., \& Zhang, J. (2017). Preparation of 4-vinylpyridine (4VP) resin and its adsorption performance for heavy metal ions. RSC Advances, 7(8), 4226-4236. http:// dx.doi.org/10.1039/C6RA26813G.

2. Xia, J., Zhang, X., \& Matyjaszewski, K. (1999). Atom transfer radical polymerization of 4-vinylpyridine. Macromolecules, 32(10), 3531-3533. http://dx.doi.org/10.1021/ma9816968.

3. Gopinath, A., Sathiyaraj, S., \& Nasar, A. S. (2017). Star poly (4-vinylpyridine) s using dendritic ATRP initiators: Synthesis, electrolyte property and performance in dye sensitized solar cell. Journal of Polymer Research, 24(8), 116. http://dx.doi. org/10.1007/s10965-017-1274-8.

4. Zhang, Z., Sèbe, G., Wang, X., \& Tam, K. C. (2018). Gold nanoparticles stabilized by poly (4-vinylpyridine) grafted cellulose nanocrystals as efficient and recyclable catalysts. Carbohydrate Polymers, 182, 61-68. http://dx.doi.org/10.1016/j. carbpol.2017.10.094. PMid:29279126.

5. Tanum, J., Han, U., Shin, J. W., \& Hong, J. (2018). Preparation of multifunctional micelles from two different amphiphilic block copolymers. Colloids and Surfaces. A, Physicochemical and Engineering Aspects, 537, 566-571. http://dx.doi.org/10.1016/j. colsurfa.2017.10.042.

6. Luo, S., Liu, S., Xu, J., Liu, H., Zhu, Z., Jiang, M., \& Wu, C. (2006). A stopped-flow kinetic study of the assembly of interpolymer complexes via hydrogen-bonding interactions. 
Macromolecules, 39(13), 4517-4525. http://dx.doi.org/10.1021/ ma060581y.

7. Xiang, M., Jiang, M., Zhang, Y., Wu, C., \& Feng, L. (1997). Intermacromolecular complexation due to specific interactions 4. The hydrogen-bonding complex of vinylphenol-containing copolymer and vinylpyridine-containing copolymer. Macromolecules, 30(8), 2313-2319. http://dx.doi.org/10.1021/ ma9614611.

8. Liu, F., \& Eisenberg, A. (2003). Synthesis of Poly (tert-butyl acrylate)-block-Polystyrene-block-Poly(4-vinylpyridine) by Living Anionic Polymerization. Angewandte Chemie International Edition, 42(12), 1404-1407. http://dx.doi. org/10.1002/anie.200390361. PMid:12671981.

9. Matsuno, R., Yamamoto, K., Otsuka, H., \& Takahara, A. (2004). Polystyrene-and poly (3-vinylpyridine)-grafted magnetite nanoparticles prepared through surface-initiated nitroxidemediated radical polymerization. Macromolecules, 37(6), 2203-2209. http://dx.doi.org/10.1021/ma035523g.

10. Convertine, A. J., Sumerlin, B. S., Thomas, D. B., Lowe, A. B., $\&$ McCormick, C. L. (2003). Synthesis of block copolymers of 2-and 4-vinylpyridine by RAFT polymerization. Macromolecules, 36(13), 4679-4681. http://dx.doi.org/10.1021/ma0343611.

11. Qi, Y., Perepichka, I. I., Song, Z., \&Varshney, S. K. (2018). Synthesis and thermal properties of poly (vinylcyclohexane)b-poly (4-vinylpyridine) diblock copolymers prepared via RAFT polymerization. e-Polymers, 18(2), 197-203. https:// doi.org/10.1515/epoly-2017-0102

12. Yang, R., Wang, Y., Wang, X., He, W., \& Pan, C. (2003). Synthesis of poly(4-vinylpyridine) and block copoly (4-vinylpyridine-bstyrene) by atom transfer radical polymerization using 5,5,7,12,12,14-hexamethyl-1,4,8,11-tetraazamacrocyclotetradecane as ligan. European Polymer Journal, 39(10), 2029-2033. http:// dx.doi.org/10.1016/S0014-3057(03)00070-3.

13. Corrigan, N., Jung, K., Moad, G., Hawker, C. J., Matyjaszewski, K., \& Boyer, C. (2020). Reversible-Deactivation Radical Polymerization (Controlled/Living Radical Polymerization): From Discovery to Materials Design and Applications. Progress in Polymer Science, 111, 101311. http://dx.doi.org/10.1016/j. progpolymsci.2020.101311.

14. Grubbs, R. B. (2011). Nitroxide-mediated radical polymerization: limitations and versatility. Polymer Reviews (Philadelphia, Pa.), 51(2), 104-137. http://dx.doi.org/10.1080/15583724.2 011.566405 .

15. Hill, M. R., Carmean, R. N., \& Sumerlin, B. S. (2015). Expanding the scope of RAFT polymerization: recent advances and new horizons. Macromolecules, 48(16), 5459-5469. http://dx.doi. org/10.1021/acs.macromol.5b00342.
16. Matyjaszewski, K. (2018). Advanced Materials by Atom Transfer Radical Polymerization. Advanced Materials, 30(23), 1706441. http://dx.doi.org/10.1002/adma.201706441. PMid:29582478.

17. Lou, Q., \& Shipp, D. A. (2012). Recent developments in atom transfer radical polymerization (ATRP): methods to reduce metal catalyst concentrations. ChemPhysChem, 13(14), 3257-3261. http://dx.doi.org/10.1002/cphc.201200166. PMid:22539367.

18. Nguyen, T. H., Nguyen, L.-T. T., Nguyen, V. Q., Phan, L. N. T., Zhang, G., Yokozawa, T., Phung, D. T. T., \& Nguyen, H. T. (2018). Synthesis of poly (3-hexylthiophene) based rod-coil conjugated block copolymers via photoinduced metal-free atom transfer radical polymerization. Polymer Chemistry, 9(18), 2484-2493. http://dx.doi.org/10.1039/C8PY00361K.

19. Corrigan, N., Shanmugam, S., Xu, J., \& Boyer, C. (2016). Photocatalysis in organic and polymer synthesis. Chemical Society Reviews, 45(22), 6165-6212. http://dx.doi.org/10.1039/ C6CS00185H. PMid:27819094.

20. Treat, N. J., Sprafke, H., Kramer, J. W., Clark, P. G., Barton, B. E., Read de Alaniz, J., Fors, B. P., \& Hawker, C. J. (2014). Metal-free atom transfer radical polymerization. Journal of the American Chemical Society, 136(45), 16096-16101. http:// dx.doi.org/10.1021/ja510389m. PMid:25360628.

21. Pan, X., Lamson, M., Yan, J., \& Matyjaszewski, K. (2015). Photoinduced metal-free atom transfer radical polymerization of acrylonitrile. ACS Macro Letters, 4(2), 192-196. http:// dx.doi.org/10.1021/mz500834g.

22. Theriot, J. C., Miyake, G. M., \& Boyer, C. A. (2018). N,N-Diaryl Dihydrophenazines as Photoredox Catalysts for PET-RAFT and Sequential PET-RAFT/O-ATRP. ACS Macro Letters, 7(6), 662-666. http://dx.doi.org/10.1021/acsmacrolett.8b00281. PMid:30705782.

23. Pearson, R. M., Lim, C.-H., McCarthy, B. G., Musgrave, C. B., \& Miyake, G. M. (2016). Organocatalyzed atom transfer radical polymerization using $\mathrm{N}$-aryl phenoxazines as photoredox catalysts. Journal of the American Chemical Society, 138(35), 11399-11407. http://dx.doi.org/10.1021/ jacs.6b08068. PMid:27554292.

24. Wu, K., Wang, Y., \& Hwu, W. (2003). FTIR and TGA studies of poly (4-vinylpyridine-co-divinylbenzene)-Cu (II) complex. Polymer Degradation \& Stability, 79(2), 195-200. http://dx.doi. org/10.1016/S0141-3910(02)00261-6.

25. Orwoll, R. A., \& Chong, Y. S. (1999). Polyacrylamide. In J. E. Mark (Eds.), Polymer data handbook (pp. 247-51). United Kingdom: Oxford University Press.

Received: Sep. 26, 2020

Revised: Feb. 09, 2021

Accepted: Feb. 10, 2021 